\title{
Hyperventilation beyond fight/flight: Respiratory responses during emotional imagery
}

\author{
ILSE VAN DIEST, ${ }^{\mathrm{a}}$ WINNIE WINTERS, ${ }^{\mathrm{a}}$ STEPHAN DEVRIESE, ${ }^{\mathrm{a}}$ ELKE VERCAMST, \\ JIANG N. HAN, ${ }^{\mathrm{b}}$ KAREL P. VAN DE WOESTIJNE, ${ }^{\mathrm{c}}$ AND OMER VAN DEN BERGH ${ }^{\mathrm{a}}$ \\ ${ }^{a}$ Department of Psychology, University of Leuven, Belgium \\ ${ }^{\mathrm{b}}$ Department of Pneumology, Peking Union Medical College Hospital, People's Republic of China \\ ${ }^{\mathrm{c}}$ Faculty of Medicine, University of Leuven, Belgium
}

\begin{abstract}
Hyperventilation (HV) is often considered part of a defense response, implying an unpleasant emotion (negative valence) combined with a strong action tendency (high arousal). In this study, we investigated the importance of arousal and valence as triggers for HV responses. Forty women imagined eight different scripts varying along the arousal and valence dimensions. The scripts depicted relaxation, fear, depressive, action, and desire situations. After each trial, the imagery was rated for valence, arousal, and vividness. $\mathrm{FetCO}_{2}$, inspiratory and expiratory time, tidal volume, and pulse rate were measured in a nonintrusive way. $\mathrm{FetCO}_{2}$ drops and decreases in inspiratory and expiratory time occurred in all but the depressive and the relaxation scripts, suggesting that a defense conceptualization of hyperventilation is not always appropriate.
\end{abstract}

Descriptors: Respiration, Hyperventilation, Emotions, Imagery

Hyperventilation or breathing in excess of metabolic needs is associated with hypocapnia, a decreased $\mathrm{CO}_{2}$ pressure $\left(\mathrm{pCO}_{2}\right)$ in the arterial blood (Gardner, 1996). Alveolar $\mathrm{pCO}_{2}$ is considered a valid approximation of arterial $\mathrm{pCO}_{2}$ and can, in turn, be reliably estimated by measuring the end-tidal fractional $\mathrm{CO}_{2}$ concentration $\left(\mathrm{FetCO}_{2}\right.$; Gardner, 1996; Pahn, Tremer, Lee, \& Barker, 1987). Both an increase in breathing frequency (number of breathing cycles per minute) and an increase in tidal volume or a combination of both may induce hyperventilation (Garssen, 1986). Ever since Cannon (1929), stress-induced hyperventilation has been viewed as the respiratory component of the fight/flight response. From this perspective, the decrease in the arterial $\mathrm{pCO}_{2}$ can be considered a feed-forward response compensating for the increased $\mathrm{CO}_{2}$ production of the physical action implied by fighting or fleeing.

In a clinical perspective, the conceptualization of hyperventilation as a fight/flight response or, in more modern terms, as a defense reaction (Turpin, 1986), has been linked to the experience of highly arousing negative emotions. Both laboratory and clinical studies showing significant $\mathrm{pCO}_{2}$ drops in situations of stress, fear, and/or pain have corroborated this (e.g., Allen, Sherwood, \& Obrist, 1986; Alpers, Wilhelm, \& Roth, 2000; Beckmann, 1915;

This study was supported by a grant of the Regering van de Vlaamse Gemeenschap (BIL 98/03). The authors thank Dr. Debora Vansteenwegen and Dr. Julian F. Thayer for their comments on an earlier draft of this article and Michel Cauberghs for his technical assistance.

Address reprint requests to: Ilse Van Diest, Department of Psychology, University of Leuven, Tiensestraat 102, B-3000 Leuven, Belgium, Ilse.VanDiest@psy.kuleuven.ac.be.
Dudley, 1969; Dudley, Masuda, Martin, \& Holmes, 1965; Garssen, 1980; Ley \& Yelich, 1998; Suess, Alexander, Smith, Sweeney, \& Marion, 1980).

However, in a broader psychophysiological perspective, several studies and reviews suggest that respiratory responding in general reflects the action tendency underlying an emotion. Consequently, within the two-dimensional affective space of emotions (Lang, Bradley, \& Cuthbert, 1990; Mehrabian \& Russell, 1974) respiration covaries particularly with arousal. For example, Nyklíček, Thayer, and Van Doornen (1997) found that emotions can be discriminated most successfully by the respiratory component, which was related to the arousal dimension. In their review, Boiten, Frijda and Wientjes (1994) propose three dimensions underlying respiratory responding. It is striking that none of those proposed dimensions refer to (un)pleasantness. The first dimension they distinguished is excitement, ranging from "passive withdrawal from the environment" to "active engagement." This seems to reflect arousal, namely a diffuse readiness for action and an increased perceptual sensitivity. Within the realm of respiratory hyperfunction, they define a second dimension, running from controlled activation and tenseness on the one extreme, to excitement, unstrained activation, and overt panic on the other. This dimension appears more related to activation, as conceptualized by Pribram (1981). The third dimension described by Boiten et al. (1994) reflects the metabolic appropriateness of the breathing, extending from normoventilation to hyperventilation.

Unfortunately, most studies investigating respiratory changes during emotions other than anxiety did not administer $\mathrm{pCO}_{2}$ measures. An exception to this is the study by Dudley (1969). This author found $\mathrm{pCO}_{2}$ drops under hypnosis during imagined anxiety 
and anger but not during depression, suggesting that arousal may explain more variance in $\mathrm{pCO}_{2}$ drops than valence. In another paper, Dudley and Pitts-Poarch (1980, p. 133) stated that " $[\mathrm{t}] \mathrm{he}$ correlation of respiratory hyperfunction and associated affect with action-oriented behavior indicates the preparation to escape, alleviate, or remove a stressful stimulus or engage in pleasurable pursuits." In the same way as Boiten et al. (1994), this author sees emotionally induced respiratory changes as exclusively determined by the action tendency underlying the emotion. In that case, hyperventilation responses should also show up during pleasant emotions. Some older studies suggest, indeed, that hyperventilation is a common response during coitus, although these studies do not report $\mathrm{pCO}_{2}$ measurements either (Bartlett, 1956; Masters \& Johnson, 1966).

To our knowledge, the present study is the first to investigate variations in $\mathrm{pCO}_{2}$ within the two-dimensional affective space. To this end, healthy women imagined themselves as active participants in eight situations varying along the dimensions of arousal (high, low) and valence (negative, positive). Script-driven imagery is considered a valid tool to elicit emotions both in psychophysiological studies (Lang, 1979; Lang, Levin, Miller, \& Kozak 1983) and in PET studies on the neuroanatomy of emotions (Davidson \& Irwin, 1999; Dougherty et al., 1999; Lane, Reiman, Ahern, Schwartz, \& Davidson, 1997). Following Lang's bio-informational theory (Lang, 1979) emotional imagery elicits physiological activity in the response channels affected by the actual emotional context. Therefore, imagery is particularly suited for the study of physiological concomitants of emotions. Also in respiratory physiology, mental imagery has extensively been used in studies on the role of feed-forward control mechanisms of higher nerve centers in exercise hyperpnea (Gallego, Denot-Ledunois, Vardon, \& Perruchet, 1996).

In line with a general psychophysiological perspective, we hypothesized that $\mathrm{pCO}_{2}$ drops would mainly reflect the response requirements of a situation, that is, would occur during imagery of both pleasant and unpleasant high arousal scripts (Hypothesis 1). However, in line with a clinical perspective, respiratory behavior may additionally be affected by specific "defense" conditions (Hypothesis 2). Therefore, we will test whether fear scripts trigger stronger responses than another equally highly arousing, pleasant script.

\section{Method}

\section{Participants}

Forty healthy women, ${ }^{1}$ all undergraduate psychology students aged 17-19 years, participated in return for course credit. Due to a technical failure, pulse rate data were unreliable for two participants.

\section{Materials}

Scripts. Following Lang (1979), the quality of emotional imagery is enhanced when, in addition to stimulus and meaning information, also response information is included in the imagery script (Lang, Kozak, Miller, Levin, \& McLean, 1980; Lang et al., 1983).

${ }^{1}$ Because men and women differ as regards respiratory volume parameters (Dhokalia, Parsons, \& Anderson, 1998; Han, Stegen, De Valck, Clément, \& Van de Woestijne, 1996; Han, Stegen, Simkens, et al., 1997), adding men would have added more error variance to the design without balancing the numbers. The latter was not possible for practical reasons. In addition, we had no a priori reasons to expect differences among men and women as regards the main research questions.
Table 1. Some Typical Phrasings Describing Each Script.

D You should be getting up, but you don't want to start the day. ... What is the use of it all? ... tired and heavy. ... empty inside and listless.

F1 You're feeling warm, and your chest is starting to feel a bit tight.... There is not enough air in the elevator.... All you can think of is "I want to get out."

F2 ... you see the huge pile of textbooks on the bookshelf. You haven't as yet made a serious go at this stuff, and exams will start soon.... You break into a sweat and your heart is pounding and your chest is feeling tight ...

Des $\quad .$. at the airport to pick up your boyfriend. He went abroad to study a year ago, ... You feel your face blushing. ... Your chest and throat feel tight.

R1 You are sitting in the back seat of a car. ... It is a calm, quiet and misty day. ... little traffic ... Lampposts pass by at a regular pace.

R2 ... an apartment overlooking the sea.... Sunbeams come in through the window, giving your body a warm comfortable glow. ... The sea is calm.

R3 A Sunday afternoon at home ... reading a book. The living room is cozy. ... you look out of the window. Outside, it is a sunny autumn day.

A ... running competition. ... your legs are moving faster and faster, your arms swinging in the same rhythm .... you break into a sweat; your system craves oxygen.

Note: D: depressive script; F1: fear 1 (elevator) script; F2: fear 2 (exam) script; Des: desire script; R1: first relaxation script; R2: second relaxation script; R3: third relaxation script; A: action script.

However, because of both automatic and voluntary influences upon breathing (Gallego et al., 1996), no phrasings directly referring to respiratory behavior were included in order to avoid specific demand effects.

Eight different imagery scripts ${ }^{2}$ were presented to each participant: three relaxation (positive valence, low arousal), two fear (negative valence, high arousal), one depressive (negative valence, low arousal), one action (neutral valence, high arousal) and one "desire" script (positive valence, high arousal). It took between 50 and $60 \mathrm{~s}$ to read the script to the participant. Table 1 contains some phrases from each script, with emphasis on illustrating references to respiration included in the scripts. The scripts were selected based on the results of a pilot study in which another group of participants had rated them on arousal and valence.

Apparatus and physiological recordings. The participants sat in a comfortable chair in a room adjacent to the equipment room. A video camera in the participant's room allowed the experimenter to monitor the participant's movements. Imagery scripts were presented via a Sony MDR-CD270 headphone plugged into the headphone jacket of a PC. A Novametrix Tidal Wave Sp hand-held capnograph/oximeter measured pulse rate (range: 30-250 bpm; accuracy: $1 \%$ of full scale). Its memory retained mean values over $8 \mathrm{~s}$, which were extracted by the Novacom software via a RS232 serial port communication. The oximeter's finger sensor was attached to the participant's left forefinger.

\footnotetext{
${ }^{2}$ The scripts are available from the authors upon request.
} 
FetCO $\mathrm{C}_{2}$ was measured using a nasal $\mathrm{CO}_{2}$-sampling cannula connected to a nondispersive infrared $\mathrm{CO}_{2}$ monitor with a resolution of $1 \mathrm{mmHg}$ and an accuracy of $\pm 2 \mathrm{mmHg}$ (Capnograph, Poet $\mathrm{RC}$, Criticare, USA).

Ventilation was measured using a respiratory inductive plethysmograph (Respitrace Corporation Model 150, New York). The coils of the Respitrace were stuck to the skin, one around the rib cage under the axilla and the other on the abdomen above the pelvis. The calibration procedure consisted of a 5-min period of breathing during which respiration was measured simultaneously by means of a pneumotachograph (Fleisch No 2, Switzerland) and the Respitrace. Both the Respitrace and the pneumotachograph signals were sampled at $20 \mathrm{~Hz}$. A multiple linear regression was performed over the calibration period, yielding the regression coefficients to be used for the reconstruction of the volume out of the Respitrace signals (Strömberg, Dahlbäck, \& Gustafsson, 1993). The multiple linear regression approach produces accurate volume data when $R^{2}>85 \%$ (Han, 1995; Han, Stegen, Cauberghs, \& Van de Woestijne, 1997). We excluded the data of only one participant because of not meeting this criterion. A Labmaster Card and a PC processed the Respitrace signals and the $\mathrm{FetCO}_{2}$ signals with a sampling rate of $20 \mathrm{~Hz}$. The $\mathrm{FetCO}_{2}$ signal and the reconstructed volume were plotted as a function of time and visually inspected for technical abnormalities and movement artifacts. Specific software extracted breathing pauses and irregularities and determined the following parameters for each breath: inspiratory and expiratory time in seconds, inspiratory and expiratory volume in milliliters and $\mathrm{FetCO}_{2}$ in percentage. Only inspiratory volume was used as a measure of tidal volume. Breathing frequency was calculated off-line out of inspiratory and expiratory time.

\section{Procedure}

Students were invited to participate in an experiment announced to investigate physiological changes during imagery. Upon arrival, the experimenter told participants that there were eight different imagery trials, each consisting of the same consecutive phases. These were explained as Baseline: When the light was dimmed, participants closed their eyes and 1 min of relaxing music was presented through the headphone (a fragment of Sarabande, Goldberg Suite, E. Grieg). Participants were instructed simply to listen to the music and relax. Script: during the following minute the script was presented and participants were asked to start the imagery as soon as they heard the text. Silence: $90 \mathrm{~s}$ of silence during which they had to keep on imagining the script as vividly as possible. After $60 \mathrm{~s}$, a low level short auditory signal, announced during the instructions, was given as a reminder to continue the imagery as vividly as possible. Recovery: Thereafter followed a recovery period of $60 \mathrm{~s}$ with another piece of relaxing music (Gymnopédie no. 1, E. Satie). As soon as this music started, participants had to stop the imagery, to keep their eyes closed and to listen to the music. The light being turned on announced the end of an imagery trial.

Participants were told that physiological recordings would be made during imagery and the purpose of the equipment was described. They were told that the finger sensor measured pulse rate, that the nose cannula sampled the expired air to send it to an analyzer and that the two coils would be attached to their rib cage and abdomen to detect changes in posture and muscle tonus of the trunk. The latter explanation was given to avoid drawing the participant's attention to her respiration. Subsequently, the participant was invited to take a quick look in the equipment room. Back in the participants' room, they filled out an informed consent form.
Next, the two coils of the Respitrace, the nose cannula, and the finger sensor were attached. The participant was asked to sit down leaning on the back of the seat, to keep both feet on the floor, and to place the hands on the legs. The experimenter checked whether this position was comfortable, and explained that they should keep the same position during the experiment. Next, the calibration procedure was started. To this end, participants wore a noseclip and breathed through a mouthpiece that was connected to a pneumotachograph.

After the calibration phase, the importance of imagining the scene as vividly as possible was emphasized. It was explained that this implied not only creating a detailed visual picture of the scene, but especially trying to feel and experience the depicted scene as if she was a real, active participant. Finally, the consecutive phases of the imagery trial were briefly repeated. All participants received the same relaxation script during the first imagery trial. Next, the experimenter went to the participant room and asked whether the participant had succeeded in imaging the scene as a real participant. Lang et al. (1980) demonstrated that emotional imagery may be enhanced by prior training in response orientation. To this end, postimagery verbal reports were elicited and the experimenter reinforced all comments referring to autonomic response activity.

The participant rated her experience during imagery on the basic affective dimensions of pleasure-displeasure and arousalcalm (Lang et al., 1990; Mehrabian \& Russell, 1974), using a paper-and-pencil version of the 9-point Manikin rating system of Bradley and Lang (1994). Also, the vividness of the imagery was rated on a 9-point Likert scale ranging from very good (1) to very poor (9).

The action script was presented as the second script. When the participants had completed the ratings of this second imagery trial, the experimenter returned to the participant's room a last time and reinforced again response-oriented descriptions of the imagery experience. The experimenter explained that the following six scripts would be presented according to the same scheme. The action script was always followed by the second relaxation script. The five remaining scripts were presented in a semirandomized way, leading to five possible presentation orders. The participants were randomly allocated (eight participants per presentation order).

Following the final imagery trial, the participants filled out a Dutch translation of the Questionnaire Upon Mental Imagery (QMI) (Sheehan, 1967). In addition, the experimenter asked whether they had voluntarily controlled their breathing during one or more imagery trials.

\section{Data Reduction and Analysis}

To avoid potential confounding by presentation order or amount of response training, data regarding the first three imagery trials (first relaxation script, action script, and second relaxation script) were left out of the analyses.

The subjective ratings on valence, arousal, and imagery vividness were analyzed using one-way ANOVAs (five levels of script: depressive, fear 1, fear 2, desire, relaxation 3) and Tukey's HSD tests for post hoc comparisons. Greenhouse-Geisser corrections were applied to these and all subsequent ANOVAs including the SCRIPT factor (five levels).

To check for baseline differences in breathing behavior between trials, means of $\mathrm{FetCO}_{2}$, inspiratory and expiratory time, breathing frequency, tidal volume, and pulse rate of the last $30 \mathrm{~s}$ of baseline were analyzed in an ANOVA with script (five levels) as a within-subject variable. For the same parameters, change scores subtracting the last $30 \mathrm{~s}$ of baseline from the mean of the last $30 \mathrm{~s}$ 
of script presentation and the $90 \mathrm{~s}$ of silence were calculated and analyzed in ANOVAs with script (five levels) as a within-subject variable. Tukey HSD tests were used for post hoc comparisons.

\section{Results}

\section{Subjective Ratings}

As shown in Table 2, the depressive and both fear scripts were rated equally on pleasantness and more negatively than the relaxation and the desire scripts, $F(4,156)=167, p<.01, \epsilon=.84$. The latter were equally positive.

The relaxation script was less arousing than the depressive script, which in turn was less arousing than the desire and both fear scripts. The desire and the fear 1 (elevator) script were more arousing than the fear 2 (exam) script, $F(4,156)=156, p<.01$, $\epsilon=.75$ (see Table 2).

The participants rated their imagery of the fear 2 (exam) script as less vivid than the relaxation script, $F(4,156)=3.43, p<.05$, $\epsilon=.89$ (see Table 2).

\section{Physiological Data}

Baseline. There were no baseline differences among the five imagery trials on any parameter $\left(F \mathrm{~s}[4,156]\right.$ were for $\mathrm{FetCO}_{2}: 0.60$, $\epsilon=.86$; for inspiratory time: $0.99, \epsilon=.52$; for expiratory time: 1 , $\epsilon=.70$; for breathing frequency: $0.58, \epsilon=.86$; for tidal volume: $0.26, \epsilon=.68$; for pulse rate: $F[4,148]=1.82, \epsilon=.87$; see Table 3 for means and $S D \mathrm{~s}$ ).

Imagery. Table 4 displays the mean change scores and $S D$ s during imagery. Decreases in $\mathrm{FetCO}_{2}$ occurred in all but the relaxation and depressive scripts, $F(4,156)=40.19, p<.01, \epsilon=$ .35 (see Figure 1). This effect was stronger for the fear 1 (elevator) script than for the desire script (see Table 4).

Scripts were associated with differences in breathing frequency, $F(4,156)=27.16, p<.01, \epsilon=.54$ : increases in breathing frequency were only observed in the high arousal scripts, and these effects were stronger for the fear 1 (elevator) than for the desire script (see Table 4). Expiratory time decreased in the desire and both fear scripts but not in the relaxation and the depressive scripts, $F(4,156)=18.07, p<.01, \epsilon=.93$ (see Table 4). Inspiratory time showed a similar, but weaker response pattern, $F(4,156)=11.09$,

Table 2. Means on the Subjective Ratings for Each Imagery Trial $(N=40)$

\begin{tabular}{lcllllllll}
\hline \hline & & $\mathrm{D}$ & $\mathrm{F} 1$ & $\mathrm{~F} 2$ & $\mathrm{D}$ s & $\mathrm{R} 3$ & $\mathrm{R} 1$ & $\mathrm{R} 2$ & $\mathrm{~A}$ \\
\hline Valence & $M$ & $7.18_{\mathrm{a}}$ & $7.88_{\mathrm{a}}$ & $7.75_{\mathrm{a}}$ & $2.13_{\mathrm{b}}$ & $2.53_{\mathrm{b}}$ & 2.95 & 1.65 & 4.53 \\
& $S D$ & 1.63 & 1.40 & 1.24 & 1.38 & 1.50 & 1.72 & .89 & 1.49 \\
Arousal & $M$ & $3.50_{\mathrm{a}}$ & $7.30_{\mathrm{b}}$ & $6.30_{\mathrm{c}}$ & $7.55_{\mathrm{b}}$ & $1.75_{\mathrm{d}}$ & 2.35 & 1.92 & 6.07 \\
& $S D$ & 1.65 & 1.62 & 1.59 & 1.36 & 1.24 & 1.63 & 1.58 & 1.74 \\
Vividness & $M$ & $4.08_{\mathrm{ab}}$ & $4.20_{\mathrm{ab}}$ & $4.45_{\mathrm{a}}$ & $3.58_{\mathrm{ab}}$ & $3.18_{\mathrm{bc}}$ & 3.28 & 2.83 & 4.43 \\
& $S D$ & 2.22 & 1.84 & 2.01 & 1.85 & 1.74 & 1.57 & 1.55 & 1.91 \\
& & & & & & & & &
\end{tabular}

Notes: D: depressive script; F1: fear 1 (elevator) script; F2: fear 2 (exam) script; Des: desire script; R3: third relaxation script; R1: first relaxation script; R2: second relaxation script; A: action script. R1, R2, and Action were not included in the analysis. Lower values indicate less aroused, more positive, or more vivid imagery, all on a 1-9 scale.

Means having the same subscript are not significantly different at $p<.05$ in the Tukey honestly significant difference comparison.
Table 3. Mean $\mathrm{FetCO}_{2}$ (in \%), Ti and Te (in s), $f$ (per minute), Vt (in $\mathrm{ml}$ ), and Pulse Rate (in bpm) During the Last 30 s of Baseline.

\begin{tabular}{lccccccccc}
\hline \hline & & $\mathrm{D}$ & $\mathrm{F} 1$ & $\mathrm{~F} 2$ & $\mathrm{Des}$ & $\mathrm{R} 3$ & $\mathrm{R} 1$ & $\mathrm{R} 2$ & $\mathrm{~A}$ \\
\hline $\mathrm{FetCO}_{2}$ & $M$ & 4.97 & 4.96 & 4.98 & 4.98 & 4.96 & 4.97 & 4.97 & 5.01 \\
& $S D$ & 0.36 & 0.34 & 0.36 & 0.37 & 0.36 & 0.33 & 0.36 & 0.35 \\
$\mathrm{Ti}$ & $M$ & 1.48 & 1.45 & 1.44 & 1.46 & 1.52 & 1.57 & 1.52 & 1.50 \\
& $S D$ & 0.27 & 0.25 & 0.33 & 0.28 & 0.50 & 0.49 & 0.31 & 0.34 \\
$\mathrm{Te}$ & $M$ & 2.16 & 2.07 & 2.17 & 2.09 & 2.10 & 2.23 & 2.17 & 2.19 \\
& $S D$ & .53 & 0.38 & 0.46 & 0.45 & 0.51 & 0.59 & 0.44 & 0.59 \\
$\mathrm{f}$ & $M$ & 17.01 & 17.44 & 17.14 & 17.36 & 17.31 & 16.53 & 16.81 & 16.87 \\
& $S D$ & 2.70 & 2.36 & 2.70 & 2.68 & 2.91 & 3.08 & 2.79 & 2.75 \\
$\mathrm{Vt}$ & $M$ & 316 & 316 & 325 & 319 & 314 & 350 & 320 & 327 \\
& $S D$ & 68 & 75 & 116 & 76 & 81 & 84 & 73 & 68 \\
$\mathrm{PR}$ & $M$ & 76.08 & 76.39 & 75.52 & 76.47 & 75.26 & 77.64 & 76.13 & 76.57 \\
& $S D$ & 9.10 & 9.57 & 9.23 & 9.17 & 10.05 & 10.40 & 10.02 & 9.92 \\
& & & & & & & & & \\
\hline
\end{tabular}

Notes: D: depressive script; F1: fear 1 (elevator) script; F2: fear 2 (exam) script; Des: desire script; R3: third relaxation script; R1: first relaxation script; R2: second relaxation script; A: action script; Ti: inspiratory time; Te: expiratory time; f: breathing frequency; Vt: tidal volume; PR: pulse rate.

$\mathrm{R} 1, \mathrm{R} 2$, and Action were not included in the analyses.

$p<.01, \epsilon=.79$ (see Table 4). In contrast with expiratory time, the change in inspiratory time during imagery of the desire script did not differ significantly from any other change score in inspiratory time.

Scripts differed also significantly as regards tidal volume, $F(4,156)=3.20, p<.05, \epsilon=.77$. Imagining the fear 2 script (exam) was associated with a greater decrease in tidal volume than imagining the depressive script (see Table 4).

Pulse rate increased during imagery of the high arousal scripts and decreased during imagery of the low arousal scripts, $F(4,148)=$ 5.30, $p<.01, \epsilon=.81$. Only the increase in pulse rate during imagining the fear 2 (exam) script was significantly different from the changes during both low arousal scripts (see Table 4).

QMI. A significant correlation across participants was found between the $\mathrm{FetCO}_{2}$ drop in the high arousal scripts (averaged over the fear 1, fear 2, and desire scripts) and the QMI score ( $r=.33$, $p<.05, N=40$ ): better imagers showed stronger $\mathrm{FetCO}_{2}$ responses.

Voluntary control of breathing. No participants responded positively on the postexperimental question whether they had voluntary controlled their breathing during imagery.

\section{Discussion}

Our results clearly show that a defense reaction is not a necessary condition for hyperventilation responses: they occurred both in states of negative and positive affect. Arousal appeared to be the more important dimension in cardiorespiratory responding, which corroborates the findings of other studies using the perspective of the two-dimensional affective space (Nyklíček et al., 1997; VanoyenWitvliet \& Vrana, 1995).

We found also evidence supporting our second hypothesis that specific "defense" conditions, defined as a combination of high arousal and negative valence, would be particularly powerful to 
Table 4. Mean Change Scores in FetCO (in \%), Ti and Te (in s), $f$ (per minute), Vt (in ml), and Pulse Rate (in bpm) from Baseline to Imagery

\begin{tabular}{lcccccccrr}
\hline \hline & & $\mathrm{D}$ & $\mathrm{F} 1$ & $\mathrm{~F} 2$ & $\mathrm{D}$ s & $\mathrm{R} 3$ & $\mathrm{R} 1$ & $\mathrm{R} 2$ & $\mathrm{~A}$ \\
\hline$\Delta \mathrm{FetCO}_{2}$ & $M$ & $0.05_{\mathrm{c}}$ & $-0.36_{\mathrm{a}}$ & $-0.28_{\mathrm{ab}}$ & $-0.19_{\mathrm{b}}$ & $0.09_{\mathrm{c}}$ & 0.11 & 0.08 & -0.26 \\
& $S D$ & 0.11 & 0.40 & 0.32 & 0.25 & 0.10 & 0.12 & 0.09 & 0.28 \\
$\Delta \mathrm{Ti}$ & $M$ & $0.06_{\mathrm{b}}$ & $-0.23_{\mathrm{a}}$ & $-0.16_{\mathrm{a}}$ & $-0.12_{\mathrm{ab}}$ & $-0.01_{\mathrm{b}}$ & 0.04 & 0.13 & -0.23 \\
& $S D$ & 0.23 & 0.36 & 0.30 & 0.31 & 0.43 & 0.36 & 0.26 & 0.40 \\
$\Delta \mathrm{Te}$ & $M$ & $0.03_{\mathrm{a}}$ & $-0.43_{\mathrm{b}}$ & $-0.45_{\mathrm{b}}$ & $-0.27_{\mathrm{b}}$ & $0.07_{\mathrm{a}}$ & 0.12 & 0.12 & -0.50 \\
& $S D$ & 0.33 & 0.55 & 0.49 & 0.57 & 0.38 & 0.30 & 0.28 & 0.67 \\
$\Delta \mathrm{f}$ & $M$ & $-0.38_{\mathrm{a}}$ & $5.69_{\mathrm{c}}$ & $3.87_{\mathrm{bc}}$ & $2.90_{\mathrm{b}}$ & $-0.59_{\mathrm{a}}$ & -0.92 & -1.08 & 4.67 \\
& $S D$ & 2.02 & 6.93 & 4.24 & 4.55 & 2.04 & 1.67 & 1.83 & 5.55 \\
$\Delta \mathrm{Vt}$ & $M$ & $0.22_{\mathrm{a}}$ & $-32.98_{\mathrm{ab}}$ & $-42.78_{\mathrm{b}}$ & $-19.60_{\mathrm{ab}}$ & $-12.18_{\mathrm{ab}}$ & -9.21 & 7.43 & -31.44 \\
& $S D$ & 50.95 & 78.66 & 92.59 & 94.48 & 59.58 & 67.24 & 54.83 & 85.07 \\
$\Delta \mathrm{PR}$ & $M$ & $-0.50_{\mathrm{ab}}$ & $1.19_{\mathrm{bc}}$ & $1.42_{\mathrm{c}}$ & $0.65_{\mathrm{abc}}$ & $-0.92_{\mathrm{a}}$ & -1.16 & -1.08 & 2.47 \\
& $S D$ & 3.41 & 3.98 & 3.10 & 2.97 & 3.06 & 3.55 & 2.59 & 3.40 \\
& & & & & & & & &
\end{tabular}

Notes: D: depressive script; F1: fear 1 (elevator) script; F2: fear 2 (exam) script; Des: desire script; R3: third relaxation script; R1: first relaxation script; R2: second relaxation script; A: action script; Ti: inspiratory time; Te: expiratory time; f: breathing frequency; Vt: tidal volume; PR: pulse rate.

$\mathrm{R} 1, \mathrm{R} 2$, and Action were not included in the analyses.

Means having the same subscript are not significantly different at $p<.05$ in the Tukey honestly significant difference comparison.

cause hypocapnic overbreathing. In line with this hypothesis, we found a stronger decrease in $\mathrm{FetCO}_{2}$ in the fear 1 (elevator) script than in the desire script (see Table 4), despite equal ratings on arousal (see Table 2). However, this may be related also to other variables in the scripts not captured by the valence and arousal dimensions. For example, situations with a particular meaning such as a risk of suffocation and/or a restriction of movement triggering a powerful action tendency to escape may be more critical for hyperventilation responses. With respect to the former, it has been shown that hypoxic stimulation in decerebrated cats triggers a full-blown defense reaction, including hyperventilation (Hilton, 1982). Both risk of suffocation and restriction of movement have been emphasized in models of panic with agoraphobia (Rachman, 1997; Barlow, 1988; Bouton, Mineka, \& Barlow, 2001). Further research should point out to what extent both characteristics may inflate hyperventilation responses.

In all arousing scripts, significant $\mathrm{FetCO}_{2}$ drops were associated with a decrease in inspiratory and expiratory time. In a study

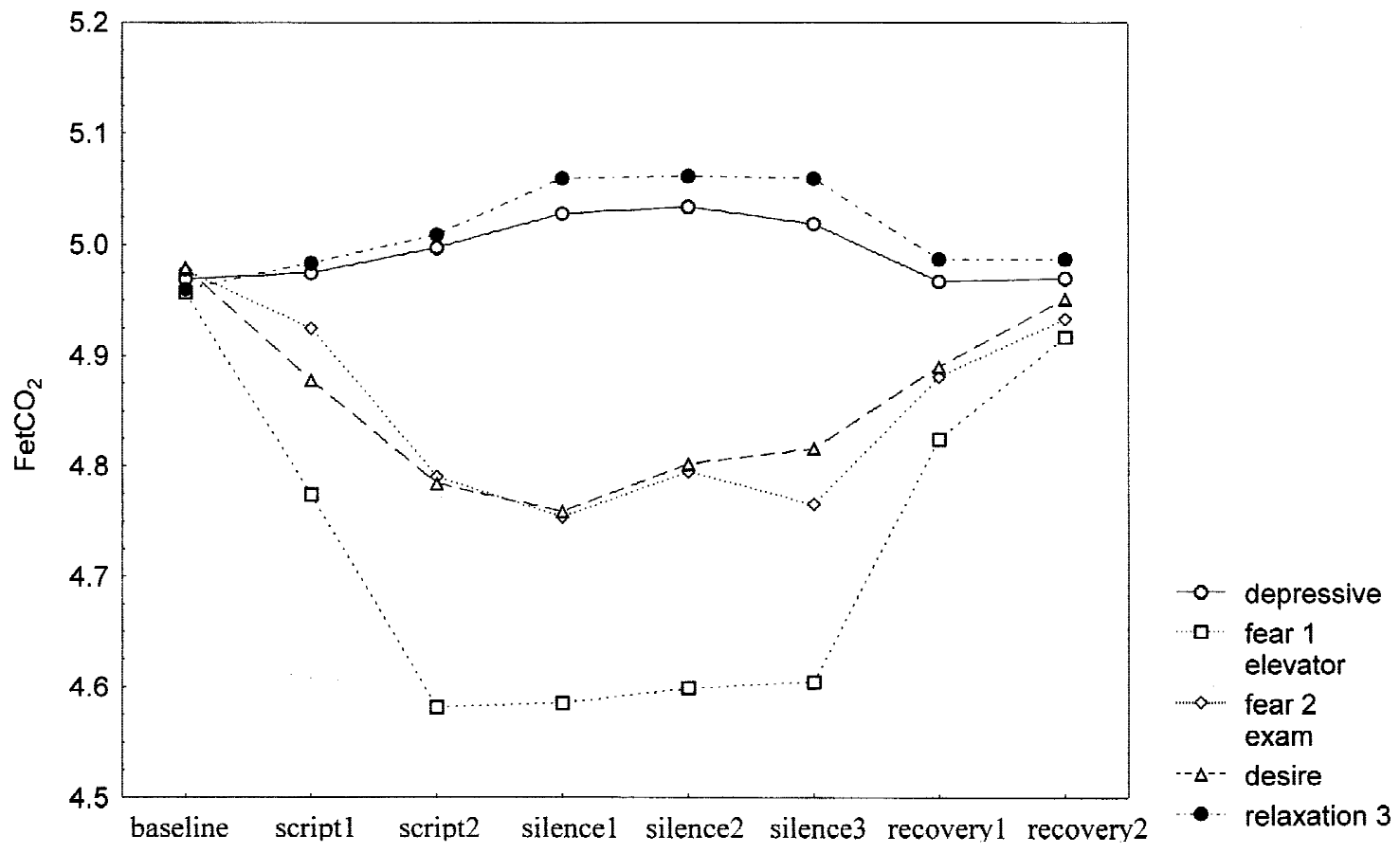

Figure 1. Mean $\mathrm{FetCO}_{2}$ (per 30-s periods) for each imagery trial (last $30 \mathrm{~s}$ of baseline, $60 \mathrm{~s}$ script, $90 \mathrm{~s}$ silence, $60 \mathrm{~s}$ recovery). 
on the control of the respiratory cycle in conscious humans, Rafferty and Gardner (1996) suggested that the respiratory timing parameters are weakly controlled by the chemical drive, which allows for the nonmetabolic functions of breathing (e.g., speech), whereas tidal volume would be controlled dominantly by the chemical drive. Our finding that timing parameters were more strongly affected than tidal volume by psychological, nonmetabolic influences (like anticipation, emotions, mental load) is consistent with results of many other studies (Anderson, Austin, \& Haythornthwaite, 1993; Denot-Ledunois, Vardon, Perruchet, \& Gallego, 1998; Mador \& Tobin, 1991; Masaoka \& Homma, 1999; Rigg, Inman, Saunders, Leeder, \& Jones, 1977; Sebej \& Biro, 1978; Turner, Carroll, \& Courtney, 1983; Wientjes, Grossman, Gaillard, \& Defares, 1993). In other studies of our group, it was found that breathing frequency, but not tidal volume could be conditioned to mental images (Stegen, De Bruyne, Rasschaert, Van de Woestijne, \& Van den Bergh, 1999) or to an unpleasant odor (Van den Bergh, Kempynck, Van de Woestijne, Baeyens, \& Eelen, 1995).

Increases in pulse rate during imagery of the high arousal scripts are rather small when compared to the increases in heart rate reported in other imagery studies (e.g., Acosta \& Vila, 1990; Carroll, Marzillier, \& Merian, 1982; Lang et al., 1980, 1983). A first reason for this may be a longer imagery period in our study (120 s) as compared to those other studies (20-50 s). We have opted for such long imagery periods to increase the reliability of our respiratory measures. Secondly, the response training in our study was limited to the first two imagery trials of the experimental session, whereas the other studies used separate training sessions lasting up to $1 \mathrm{hr}$.

An important constraint potentially limiting the conclusions of our data is that they are collected during imagined rather than real emotional scenes. One could argue that the content of the scripts may have induced demands affecting voluntary respiratory behavior. However, no single participant reported having voluntarily controlled her breathing at some point in time. Also, in another imagery study of our group (Van Diest et al., 2001), we left out all suggestions towards autonomic and respiratory responses in the fear 1 , fear 2, depressive, and the relaxation scripts and we essentially replicated the present results: significant hyperventilation responses occurred in both unpleasant and pleasant, high arousal scripts. However, the $\mathrm{FetCO}_{2}$ drops were much smaller in the study without autonomic response propositions. When comparing the current study with the study without autonomic response propositions, we found a medium effect size (.51) of response information on arousal-related changes in $\mathrm{FetCO}_{2}$ during imagery of high arousal scripts. Also, the omission of autonomic response information was associated with less imagery vividness, which is in line with Lang's (1979) bio-informational theory of emotional imagery.
The argument regarding the relevance of imagined scenes for real life can also be turned the other way round. Indeed, hyperventilation responses in humans typically result from a discrepancy between feed-forward influences upon breathing due to mental activity and the actual metabolic state. Such discrepancy may more likely emerge when people anticipate or imagine stressful events, because $\mathrm{CO}_{2}$ production may be expected to be lower compared to being in the actual situation. Considering hyperventilation an inhibition failure (Fokkema, 1999), the probability of such a failure may be expected to increase with the (evolutionary) increasing capacity of mental imagery. In this perspective, breathing responses triggered by imagery may actually be particularly relevant for hyperventilation as a clinical problem.

The levels of $\mathrm{FetCO}_{2}$ reached during high arousing imagery mostly remained within the eucapnic range, in which both feedback (chemosensitivity) and feed-forward mechanisms (e.g., anxiety/ arousal related influences; Shea, 1996) remain operational (Cunningham, Robbins, \& Wolff, 1986). However, we believe that imagining more intensely arousing scenes during a longer period may cause hyperventilation and hypocapnia up to the level where $\mathrm{CO}_{2}$ sensitivity decreases and/or the chemical drive to breathe disappears (Cunningham et al., 1986; Gardner, 1996). In normal cases, this typically causes apneas quickly restoring arterial $\mathrm{pCO}_{2}$ (Van Diest, Schippers, Stegen, Van de Woestijne, \& Van den Bergh, 2000). In clinical populations, though, the symptoms associated with low levels of $\mathrm{pCO}_{2}$ often inflate anxiety, which may further stimulate breathing and overrule normal apneas. A spiraling, panic-like process may easily ensue.

The hyperventilation responses observed in this study should be viewed as responses reflecting the anticipatory capacity of the respiratory system that are not necessarily pathological. Indeed, our results reinforce a distinction between, on the one hand, hyperventilation as a common concomitant of arousal, and on the other hand, the pathologies it may become involved with as a result of an interaction with other variables. For example, Salkovskis \& Clark (1990) showed that bodily sensations produced by hyperventilation could be interpreted both in a positive and negative way, leading to corresponding changes in affect. Also classical conditioning has been identified as a mechanism by which hyperventilation may become involved in psychosomatic pathology (Stegen et al., 1999; Van den Bergh, Stegen, \& Van de Woestijne, 1997), in multiple chemical sensitivity (Van den Bergh et al., 2001), and in panic disorder (Bouton et al., 2001).

In summary, we found hyperventilation responses during imagery of pleasant and unpleasant, high arousing situations, indicating that respiratory responding during imagery varies primarily along a broad arousal continuum. In addition, aspects not captured by the two-dimensional affective space, such as a risk of suffocation or blocked action tendencies in escape situations, may increase the tendency to hyperventilate.

\section{REFERENCES}

Acosta, A., \& Vila, J. (1990). Emotional imagery: Effect of autonomic response information on physiological arousal. Cognition and Emotion, 4, 145-160.

Allen, M. T., Sherwood, A., \& Obrist, P. A. (1986). Interactions of respiratory and cardiovascular adjustments to behavioral stressors. Psychophysiology, 23, 532-541.

Alpers, G. W., Wilhelm, F. H., \& Roth, W. T. (2000). A new ambulatory measure of hyperventilation in anxiety disorders. Biological Psychology, 53, 80 .

Anderson D. E., Austin J., \& Haythornthwaite J. A. (1993). Blood pressure during sustained inhibitory breathing in the natural environment. Psychophysiology, 30, 131-137.

Barlow, D. H. (1988). Anxiety and its disorders: The nature and treatment of anxiety and panic. New York: Guilford Press.

Bartlett, R. G., Jr. (1956). Physiologic responses during coitus. Journal of Applied Physiology, 9, 469-472.

Beckmann, K. (1915). Über Anderungen in der Atmungsregulation durch psychische und pfarmakologische Einflüsse. Archiv F ür Klinische Medizin, 117, 419-437.

Boiten, F., Frijda, N. H., \& Wientjes, C. J. (1994). Emotions and respiratory 
patterns: Review and critical analysis. International Journal of Psychophysiology, 17, 103-128.

Bouton, M. E., Mineka, S., \& Barlow, D. H. (2001). A modern learning theory perspective on the etiology of panic disorder. Psychological Review, 108, 4-32.

Bradley, M. M., \& Lang, P. J. (1994). Measuring emotion: The SelfAssessment Manikin (SAM) and the semantic differential. Journal of Experimental Psychiatry \& Behavior Therapy, 25, 49-59.

Cannon, W. B. (1929). Bodily changes in pain, fear and rage, 2 nd ed. New York: Appleton and Company.

Carroll, D., Marzillier, J. S., \& Merian, S. (1982). Psychophysiological changes accompanying different types of arousing and relaxing imagery. Psychophysiology, 19, 75-82.

Cunningham, D. J. C., Robbins, P. A., \& Wolff, C. B. (1986). Integration of respiratory responses to changes in alveolar partial pressures of $\mathrm{CO}_{2}$ and $\mathrm{O}_{2}$ in arterial pH. In N. S. Cherniak, \& J. C. Widdicombe (Eds.), Handbook of physiology. The respiratory system (vol. 2, pp. 475-528). Bethesda, MD: American Physiological Society.

Davidson, R. J., \& Irwin, W. (1999). The functional neuroanatomy of emotion and affective style. Trends in Cognitive Science, 3, 11-21.

Denot-Ledunois, S., Vardon, G., Perruchet, P., \& Gallego, J. (1998). The effect of attentional load on the breathing pattern in children. International Journal of Psychophysiology, 29, 13-21.

Dhokalia, A., Parsons, D. J., \& Anderson, D. E. (1998). Resting end-tidal $\mathrm{CO}_{2}$ association with age, gender, and personality. Psychosomatic Medicine, 60, 33-37.

Dougherty, D. D., Shin, L. M., Alpert, N. M., Pitman, R. K., Orr, S. P., Lasko, M., Macklin, L., Fischman, A. K., \& Rauch, S. L. (1999). Anger in healthy men: A PET study using script-driven imagery. Biological Psychiatry, 46, 466-472.

Dudley, D. L. (1969). Psychophysiology of respiration in health and disease. New York: Appleton-Century-Crofts.

Dudley, D. L., Masuda, M., Martin, C. J., \& Holmes, T. H. (1965). Psychophysiological studies of experimentally induced action oriented behavior. Journal of Psychosomatic Research, 9, 209-221.

Dudley, D. L., \& Pitts-Poarch, A. R. (1980). Psychophysiologic aspects of respiratory control. Clinics in Chest Medicine, 1, 131-143.

Fokkema, D. S. (1999). The psychobiology of strained breathing and its cardiovascular implications: A functional system review. Psychophysiology, 36, 164-175.

Gallego, J., Denot-Ledunois, S., Vardon, G., \& Perruchet, P. (1996). Ventilatory responses to imagined exercise. Psychophysiology, 33, 711-719.

Gardner, W. N. (1996). The pathophysiology of hyperventilation disorders. Chest, 109, 516-534.

Garssen, B. (1980). Role of stress in the development of the hyperventilation syndrome. Psychotherapy and Psychosomatics, 33, 214-225.

Garssen, B. (1986). Psychofysiologie van de ademhaling en het hyperventilatiesyndroom. Doctoral Dissertation, University of Utrecht, The Netherlands.

Han, J. N. (1995). Acta Biomedica Lovaniensia: Vol. 113, Breathing patterns in anxiety disorders: Is there a hyperventilation syndrome? Leuven: University Press.

Han, J. N., Stegen, K., Cauberghs, M., \& Van de Woestijne, K. P. (1997). Influence of awareness of the recording of breathing on respiratory pattern in healthy humans. European Respiratory Journal, 10, 161166.

Han, J. N., Stegen, K., De Valck, C., Clément, J., \& Van de Woestijne, K. P. (1996). Influences of breathing therapy on complaints, anxiety and breathing pattern in patients with hyperventilation syndrome and anxiety disorders. Journal of Psychosomatic Research, 41, 481-493.

Han, J. N., Stegen, K., Simkens, K., Caubergs, M., Schepers, R., Van den Bergh, O., Clément, J., \& Van de Woestijne, K. P. (1997). Unsteadiness of breathing in patients with hyperventilation syndrome and anxiety disorders. European Respiratory Journal, 10, 167-176.

Hilton, S. M. (1982). The defence-arousal system and its relevance for circulation and respiratory control. Journal of Experimental Biology, 100, 159-174.

Lane, R. D., Reiman, E. M., Ahern, G. L., Schwartz, G. E., \& Davidson, R. J. (1997). Neuroanatomical correlates of happiness, sadness, and disgust. American Journal of Psychiatry, 154, 926-933.

Lang, P. J. (1979). A bio-informational theory of emotional imagery. Psychophysiology, 16, 495-512.

Lang, P. J., Bradley, M. M., \& Cuthbert, B. N. (1990). Emotion, attention, and the startle reflex. Psychological Review, 97, 377-395.

Lang, P. J., Kozak, M. J., Miller, G. A., Levin, D. N., \& McLean, A. (1980).
Emotional imagery: Conceptual structure and pattern of somatovisceral response. Psychophysiology, 17, 179-192.

Lang, P. J., Levin, D. N., Miller, G. A., \& Kozak, M. J. (1983). Fear behavior, fear imagery, and the psychophysiology of emotion: The problem of affective response integration. Journal of Abnormal Psychology, 92, 276-306.

Ley, R., \& Yelich, G. (1998). Fractional end-tidal $\mathrm{CO}_{2}$ as an index of the effects of stress on math performance and verbal memory of testanxious adolescents. Biological Psychology, 49, 83-94.

Mador, M. J., \& Tobin, M. J. (1991). Effects of alterations in mental activity on the breathing pattern in healthy subjects. American Review of Respiratory Disease, 144, 481-487.

Masaoka, Y., \& Homma, I. (1999). Expiratory time determined by individual anxiety levels in humans. Journal of Applied Physiology, 86, 1329-1336.

Masters, W. H., \& Johnson, V. E. (1966). Human sexual response. Boston: Little Brown.

Mehrabian, A., \& Russell, J. A. (1974). An approach to environmental psychology. Cambridge, MA: MIT Press.

Nyklíček, I., Thayer, J. F., \& Van Doornen, L. J. P. (1997). Cardiorespiratory differentiation of musically induced emotions. Journal of Psychophysiology, 11, 304-321.

Pahn, C. Q., Tremer, K. K., Lee, S. E, \& Barker S. J. (1987). Noninvasive monitoring of carbon dioxide: A comparison of the partial pressure of transcutaneous and end-tidal carbon dioxide with the partial pressure of arterial carbon dioxide. Journal of Clinical Monitoring, 3, 149-154.

Pribram, K. H. (1981). Emotions. In S. B. Filskov, \& T. J. Boll (Eds.), Handbook of clinical neuropsychology (pp. 102-134). New York: Wiley.

Rachman, R. S. (1997). Claustrophobia. In G. C. L. Davey (Ed.), Phobias: A handbook of theory, research and treatment (pp. 163-182). New York: Wiley.

Rafferty, G. F., \& Gardner, W. N. (1996). Control of the respiratory cycle in conscious humans. Journal of Applied Physiology, 81, 1744-1753.

Rigg, J. R. A., Inman, E. M., Saunders, N. A., Leeder, S. R., \& Jones, N. L. (1977). Interaction of mental factors with hypercapnic ventilatory drive in man. Clinical Science and Molecular Medicine, , 53, 269-275.

Salkovskis, P. M., \& Clark, D. M. (1990). Affective responses to hyperventilation-A test of the cognitive model of panic. Behaviour Research and Therapy, 28, 51-61.

Sebej, F., \& Biro, V. (1978). Effect of psychic load on the course of respiration. Studia Psychologica, 20, 67-71.

Shea, S. A. (1996). Behavioural and arousal-related influences on breathing in humans. Experimental Physiology, 81, 1-26.

Sheehan, P. W. (1967). A shortened form of Bett's Questionnaire upon Mental Imagery. Journal of Clinical Psychology, 23, 386-389.

Stegen, K., De Bruyne, K., Rasschaert, W., Van de Woestijne, K. P., \& Van den Bergh, O. (1999). Fear-relevant images as conditioned stimuli for somatic complaints, respiratory behavior, and reduced end-tidal $\mathrm{pCO}_{2}$. Journal of Abnormal Psychology, 108, 143-152.

Strömberg, N. O. T., Dahlbäck, G. O., \& Gustafsson, P. M. (1993). Evaluation of various models for respiratory inductance plethysmography calibration. Journal of Applied Physiology, 74, 1206-1211.

Suess, W. M., Alexander, A. B., Smith, D. D., Sweeney, H. W., \& Marion, R. J. (1980). The effects of psychological stress on respiration: A preliminary study of anxiety and hyperventilation. Psychophysiology, 17, 535-540.

Turner, R. J., Carroll, D., \& Courtney, H. (1983). Cardiac and metabolic responses to "space invaders": An instance of metabolically exaggerated cardiac adjustment? Psychophysiology, 20, 544-549.

Turpin, G. (1986). Effects of stimulus intensity on autonomic responding: The problem of differentiating orienting and defense reflexes. Psychophysiology, 23, 1-14.

Van den Bergh, O., Devriese, S., Winters, W., Eelen, P., Veulemans, H., \& Nemery, B. (2001). Acquiring symptoms in response to odors: A learning perspective on Multiple Chemical Sensitivity. Annals of the New York Academy of Sciences, 933, 278-290.

Van den Bergh, O., Kempynck, P. J., Van de Woestijne, K. P., Baeyens, F., \& Eelen, P. (1995). Respiratory learning and somatic complaints: A conditioning approach using $\mathrm{CO}_{2}$-inhalation. Behaviour Research and Therapy, 5, 517-527.

Van den Bergh, O., Stegen, K. \& Van de Woestijne, K. P. (1997). Learning to have psychosomatic complaints: Conditioning of respiratory behavior and somatic complaints in psychosomatic patients. Psychosomatic Medicine, , 59, 13-23.

Van Diest, I., Proot, P., Van de Woestijne, K. P., Han, J. N., Devriese, S., 
Winters, W. \& Van den Bergh, O. (2001). Critical conditions for hyperventilation responses: The role of autonomic response propositions during emotional imagery. Behavior Modification, 25, 621-635.

Van Diest, I., Schippers, N., Stegen, K., Van de Woestijne, K. P., Van den Bergh, O. (2000). Hyperventilation and attention: Effects of hypocapnia on performance in a stroop task. Biological Psychology, 53, 233-252.

Vanoyen-Witvliet, C., \& Vrana, S. R. (1995). Psychophysiological responses as indices of affective dimensions. Psychophysiology, 32, $436-443$.
Wientjes, C. J. E., Grossman, P., Gaillard, A. W. K., \& Defares, P. B. (1993). Individual differences in respiration and stress. In R. Hockey, A. W. K. Gaillard, \& P. B. Defares (Eds.), Energetics and human information processing. Dordrecht, Nijhoff.

(ReCEIVED January 16, 2001; AcCePted June 25, 2001) 